\title{
Novos registros de Heliantheae Cass. (Asteraceae) para o Brasil
}

\author{
Cláudio Augusto Mondin ${ }^{1}$
}

Recebido em 27/01/2007. Aceito em 3/04/2007

\begin{abstract}
RESUMO - (Novos registros de Heliantheae Cass. (Asteraceae) para o Brasil). Quatro espécies da tribo Heliantheae (Asteraceae) encontradas no Rio Grande do Sul representam o primeiro registro para o Brasil: Acmella psilocarpa R.K. Jansen, Angelphytum grisebachii (Baker) H. Rob., Angelphytum tenuifolium (Hassl.) H. Rob. e Viguiera nudicaulis (Pers.) Baker. São apresentadas descrições e ilustrações para as espécies. Além disso, são fornecidos dados sobre a distribuição geográfica, hábitat, época de floração e frutificação.
\end{abstract}

Palavras-chave: Asteraceae, Heliantheae, Acmella Rich., Angelphytum G.M. Barroso, Viguiera Kunth

\begin{abstract}
New records of Heliantheae Cass. (Asteraceae) for Brazil). Four species of Heliantheae (Asteraceae) found in the state of Rio Grande do Sul are first reported here for Brazil: Acmella psilocarpa R.K. Jansen, Angelphytum grisebachii (Baker) H. Rob., Angelphytum tenuifolium (Hassl.) H. Rob. and Viguiera nudicaulis (Pers.) Baker. Species descriptions and illustrations are presented. Additional information is provided concerning geographic distribution, habitats and phenology.
\end{abstract}

Key words: Asteraceae, Heliantheae, Acmella Rich., Angelphytum G.M. Barroso, Viguiera Kunth

\section{Introdução}

Heliantheae enquadra-se, segundo Bremer (1994), na subfamília Asteroideae, constituindo-se numa das maiores tribos de Asteraceae, com cerca de 189 gêneros e 2.500 espécies, sendo numericamente inferior em espécies apenas a Senecioneae e Astereae. A maioria dos gêneros e espécies ocorrem na América do Norte e América do Sul, sendo, o México, o principal centro de riqueza da tribo.

Citações de espécies de Heliantheae para o Brasil são encontradas, sobretudo, em De Candolle (1836), Baker (1884), Malme (1899; 1931), Cabrera (1963; 1974) e Santos (2001). Os gêneros Acmella e Angelphytum foram revisados, respectivamente, por Jansen (1985) e Robinson (1984), enquanto Viguiera, por Blake (1918) e Robinson (2004), como Rhysolepis.

O presente trabalho reúne táxons de Heliantheae sensu stricto que representam a primeira citação de ocorrência para o Brasil. Fornece descrições, informações sobre hábitat, épocas de floração e frutificação, comentários, materiais examinados e ilustrações das espécies.

\section{Material e métodos}

As descrições das espécies são baseadas nas análises das exsicatas pertencentes às coleções dos herbários HAS, HASU, ICN, LP, MPUC, PACA, PEL e SALLE (siglas de acordo com Holmgren \& Holmgren, 1998-2006) e de observações de campo. A terminologia adotada para a descrição dos caracteres morfológicos baseia-se em Radford et al. (1974), exceto no que se refere ao indumento, que foi baseado em Harris \& Harris (2001), e aquela específica para a família Asteraceae, que segue Barroso et al. (1991) e Bremer (1994). Os sistemas sexuais são denominados de acordo com Cruden \& Lloyd (1995). São aqui considerados homógamos os capítulos constituídos por flores com a mesma organização sexual, sejam elas estaminadas, pistiladas, perfeitas ou com flores do raio neutras.

Os dados referentes ao hábitat foram obtidos através de observações de campo, do material examinado, bem como da literatura. Os dados sobre a floração e a frutificação foram baseados unicamente no material examinado do sul do Brasil.

\footnotetext{
1 Laboratório de Biologia Vegetal, Pontifícia Universidade Católica do Rio Grande do Sul, Av. Ipiranga, 6681, Prédio 12, $90619-900$ Porto Alegre, RS, Brasil (cmondin@ pucrs.br)
} 


\section{Resultados e discussão}

1. Acmella psilocarpa R.K. Jansen, Syst. bot. monogr. 8: 93. 1985. Tipo: Argentina, Entre Rios, Gualeguaychú, Dec 1936, Cabrera 3977 (holótipo LP).

Fig. 1-10

Erva perene, ramos eretos ou ascendentes, às vezes radicantes nos nós, 0,1-0,3 $\mathrm{m}$ de altura, pouco ramificada na base, ginomonóica. Caule estriado, anguloso, glabro a esparsamente pubérulo, sobretudo nos nós, castanho quando seco, folhoso na base e na porção mediana, áfilo no ápice. Folhas simples, opostas, lanceoladas, 2-5×0,4-1,2 cm, ápice agudo ou obtuso, base longamente atenuada em pseudopecíolo, margem paucidentada ou denticulada, membranáceas ou papiráceas, glabrescentes a moderadamente setulosas nas margens e sobre as nervuras em ambas as faces, trinérveas acima da base, pseudopecíolo 0,6-0,8 cm compr., glabro, canaliculado. Capítulos radiados, heterógamos, solitários no ápice dos ramos ou nas axilas das folhas superiores, longamente pedunculados, pedúnculos 7-15 cm compr., esparsamente setulosos, ebracteados ou, eventualmente, com uma brátea linearlanceolada com ca. 0,5 cm compr. Invólucro hemisférico, $3 \mathrm{~mm}$ alt., $6 \mathrm{~mm}$ diâm., brácteas involucrais bisseriadas, com aproximadamente o mesmo tamanho, ovais, elípticas ou obovais, 2,5-4×1-1,7 mm, ápice agudo, margem inteira ou erosa, membranáceas, glabras no dorso, irregularmente e moderadamente setulosas nas margens, multinérveas. Receptáculo cônico, páleas conduplicadas, carenadas, oblongolanceoladas, 3-4×1 mm, ápice subagudo, margem inteira a paucidentada no ápice, glabras ou pubérulas e moderadamente glandulosas sobre a carena. Flores do raio 7-9 por capítulo, pistiladas, unisseriadas, liguliformes, corola 5-8 $\times 1,8-2 \mathrm{~mm}$, tubo 1,2-1,5 mm compr., limbo estreitamente oblongo, ápice bidentado, densamente pilosas no tubo, amarelas. Estilete bífido, glabro. Flores do disco 60-100, monoclinas, corola tubulosa, 2-2,5 mm compr., tubo 0,5-0,7 mm compr., pentadentadas, lacínias 0,3-0,5 $\mathrm{mm}$ compr., interiormente papilosas, amarelas. Anteras com tecas castanhas, apêndice oval, eglanduloso, base curtamente sagitada. Estilete bífido, ramos do estilete com ápice truncado, pubérulo. Cipselas obovóides ou oblanceoladas, as do raio tríquetras, 1,7-1,8 mm compr., as do disco lateralmente comprimidas, 1,8-2 mm compr., glabras ou esparsamente pubescentes no ápice, pretas. Papilho ausente ou com duas (três nas cipselas do raio) aristas curtíssimas com 0,2-0,5 mm compr. Material selecionado: BRASIL. Rio Grande do Sul: Barra do Quaraí, na beira do rio Uruguai, 18/XI/2001, fl., Mondin et al. 2500 (HASU). Uruguaiana, na ponte sobre o rio Ibicuí, divisa com Itaqui, 13/XI/1984, fl. fr., Sobral 3247 (ICN).

Jansen (1985) cita a espécie para a Argentina (Entre Rios) e Brasil (Rio Grande do Sul), acrescentando que, no Rio Grande do Sul, o único registro é o da localidade-tipo. Entretanto, trata-se de um equívoco, uma vez que a localidade-tipo da espécie é Gualeguaychú, Entre Rios, Argentina e, no mapa de distribuição da espécie (Jansen 1985: 48, fig. 16), não foi assinalado nenhum ponto de ocorrência no Brasil. A espécie ocorre em áreas úmidas ao longo de rios e foi coletada com flores e frutos em novembro. Segundo Jansen (1985), floresce em novembro e dezembro.

2. Angelphytum grisebachii (Baker) H. Rob., Proc. biol. soc. wash. 97(4): 966. 1984. Tipo: Concepción del Uruguay, Lorentz 1039 (holótipo B).

Verbesina grisebachii Baker, Fl. bras. 6(3): 214. 1884. Zexmenia grisebachii (Baker) Hassl., Feddes Repert. 14:157. 1915.

Fig. 11-22

Erva perene, ereta ou ascendente, 0,3-0,6 $\mathrm{m}$ de altura, ramificada na base a partir de um xilopódio, ginomonóica. Caule cilíndrico, estriado, híspido, esverdeado, castanho quando seco, folhoso na base e na porção mediana, áfilo em direção ao ápice. Folhas simples, opostas, as superiores, às vezes, alternas, lanceoladas ou ovais, 4-8×1,7-2,7 cm, ápice agudo ou obtuso, base arredondada, margem crenado-serreada ou serreada, cartáceas, densamente híspidas e moderadamente pontuado-glandulosas em ambas as faces, trinérveas ou qüinqüenérveas, sésseis ou subsésseis, pecíolo 0-0,1 cm compr. Capítulos radiados, heterógamos, solitários no ápice dos ramos, longamente pedunculados, pedúnculos $15-42 \mathrm{~cm}$ compr., híspidos na base, albo-lanuginosos na parte superior, ebracteados. Invólucro hemisférico, 9-10 mm alt., $15 \mathrm{~mm}$ diâm., brácteas involucrais trisseriadas, dimorfas, as da série externa foliáceas, expandidas, geralmente com uma ou duas brácteas maiores que as demais, estreitamente elípticas, estreitamente oblongas ou oblanceoladas, $8-15 \times 2-5 \mathrm{~mm}$, ápice agudo a obtuso, mucronado, margem inteira ou crenada, cartáceas, densamente estrigosas e moderadamente pontuadoglandulosas, trinérveas, as internas lanceoladas, oblongo-oblanceoladas ou estreitamente oblongas, 9-10 $\times 1,5-2 \mathrm{~mm}$, margem vilosa, escariosas, dorso 


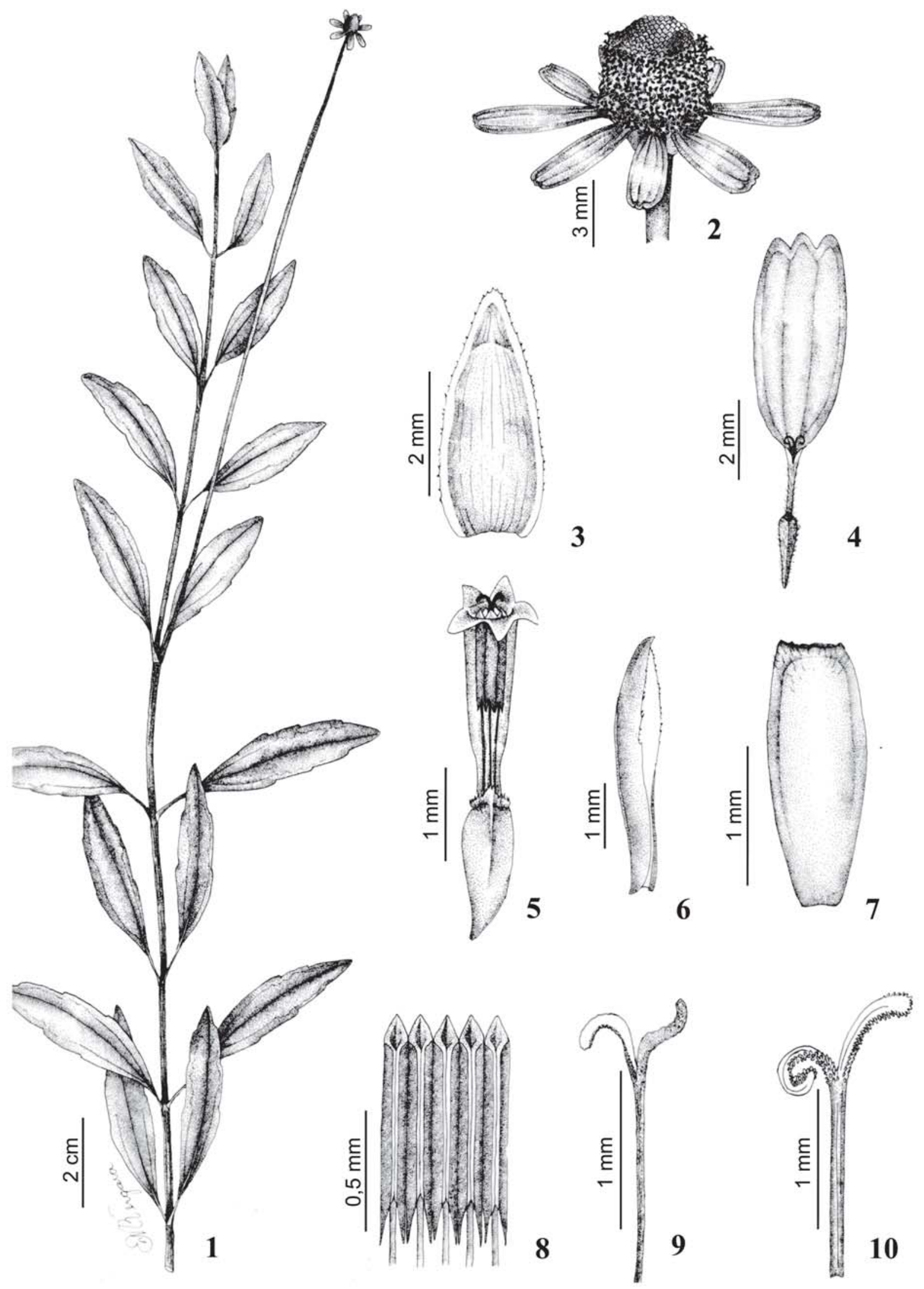

Figuras 1-10. Acmella psilocarpa R.K. Jansen. 1. Ramo florido. 2. Capítulo. 3. Bráctea involucral. 4. Flor do raio. 5. Flor do disco. 6. Pálea. 7. Cipsela do disco. 8. Anteras. 9-10. Ápice do estilete das flores do raio e do disco (Mondin et al. 2500). 


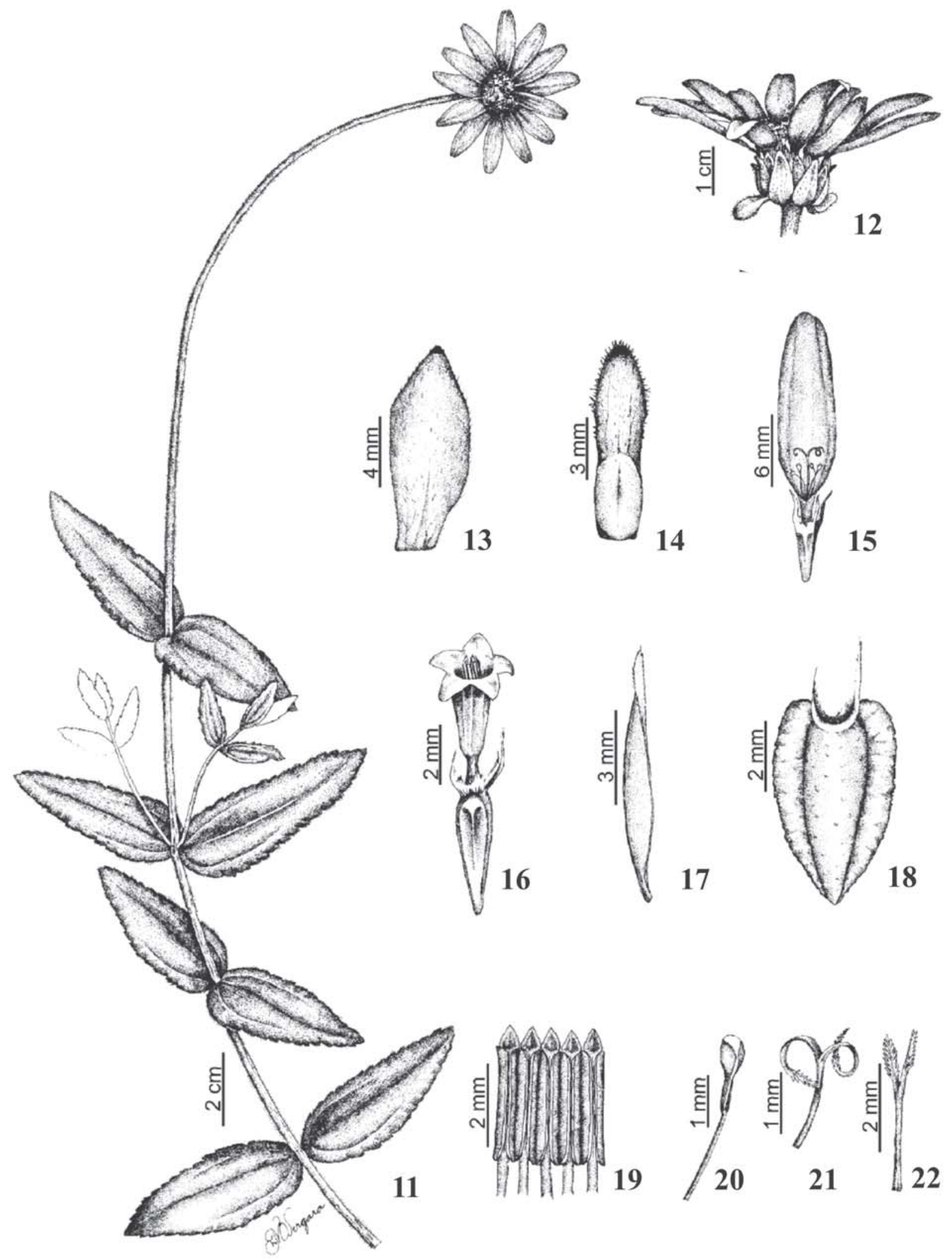

Figuras 11-22. Angelphytum grisebachii (Baker) H. Rob. 11. Ramo florido. 12. Capítulo. 13-14. Brácteas involucrais. 15. Flor do raio. 16. Flor do disco. 17. Pálea. 18. Cipsela do disco. 19. Anteras. 20. Estaminódio. 21-22. Ápice do estilete das flores do raio e do disco (Mondin \& Iob 2809). 
estrigoso, multinérveas. Receptáculo levemente convexo, páleas conduplicadas, carenadas, oblongolanceoladas, $10 \times 1,5 \mathrm{~mm}$, ápice acuminado, margem inteira, pontuado-glandulosas e laxamente pubescentes no dorso junto à carena, curtamente ciliadas no ápice. Flores do raio 14-20 por capítulo, pistiladas ou funcionalmente pistiladas, podendo apresentar dois estaminódios livres entre si, com ca. $2 \mathrm{~mm}$ compr., unisseriadas, liguliformes, corola $17 \times 6 \mathrm{~mm}$, tubo 1-1,5 mm compr., limbo estreitamente elíptico, estreitamente oblongo ou oblanceolado, ápice tridentado, glabrescentes no tubo, pontuado-glandulosas e pubérulas na face abaxial do limbo, amarelas. Estilete bífido, ramos de ápice acuminado e pubérulo. Flores do disco ca. 90, monoclinas, corola tubulosa, $5 \mathrm{~mm}$ compr., tubo ca. $1 \mathrm{~mm}$ compr., pentadentadas, lacínias 0,8-1 mm compr., pontuado-glandulosas no ápice, amarelas. Anteras com tecas enegrecidas, apêndice triangular, pontuado-glanduloso, base obtusa. Estilete bífido, ramos pubérulos com um apêndice piloso no ápice. Cipselas obovóides, sem constrição sob o papilho, as do raio tríquetras, as do disco lateralmente comprimidas, ca. $6 \mathrm{~mm}$ compr., bialadas nas flores do disco, trialadas nas flores do raio, glabras ou esparsamente pubérulas no ápice, castanho-escuras. Papilho formado por duas (três nas cipselas do raio) aristas subiguais de 1-2,5 mm compr., entremeadas por escaminhas laciniadas que diminuem de tamanho das margens, onde são soldadas às aristas, para o centro.

Material selecionado: BRASIL. Rio Grande do Sul: Manoel Viana, cerro do Negro, 16/XI/2002, fl., Mondin 2824 (HASU). Santana do Livramento, cerro Armour, 15/XI/2002, fl., Mondin \& Iob 2809 (HASU). São Vicente do Sul, cerro Loreto, XII/1985, fl., Sobral \& Marchiori 4565 (ICN).

Baker (1884), na descrição original, e Cabrera (1974) citam a espécie para a Argentina (Entre Rios) e Uruguai. Robinson (1984) acrescenta o Paraguai à sua distribuição geográfica. A espécie é citada aqui pela primeira vez para o Brasil, ocorrendo na vegetação campestre. Foi coletada com flores e frutos de novembro a janeiro.

3. Angelphytum tenuifolium (Hassl.) H. Rob., Proc. biol. soc. wash. 97(4): 969. 1984. Tipo: Paraguai, 1903, Hassler 2624 (holótipo G).

Zexmenia tenuifolia Hassl., Feddes repert. 14: 178. 1915.

Fig. 23-34

Subarbusto ereto, 0,8-1,7 m de altura, ramificado desde a base, ginomonóico. Caule cilíndrico, estriado, escabro a híspido, verde-purpúreo, castanho-claro quando seco, folhoso até o ápice. Folhas simples, opostas, lanceoladas ou ovais, 3-8,5×0,8-4 cm, ápice agudo ou apiculado, base cuneada ou arredondadoatenuada, margem serreada, papiráceas, híspidas na face adaxial, híspidas a densamente vilosas e pontuadoglandulosas na face abaxial, trinérveas acima da base, discolores, pecíolo 0,1-1,1 cm compr., híspido. Capítulos radiados, heterógamos, solitários ou reunidos em cimeiras de até três no ápice dos ramos, curtamente a longamente pedunculados, pedúnculos 2-10 cm compr., híspidos, ebracteados ou com uma bráctea foliácea lanceolada com ca. $2 \mathrm{~cm}$ compr. próximo ao capítulo. Invólucro campanulado, 8-10 mm alt., 13-15 mm diâm., trisseriado, brácteas involucrais dimorfas, as da série externa foliáceas, expandidas, de maior tamanho que as internas, às vezes ultrapassando as flores do raio, lanceoladas ou oblanceoladas, $8-25 \times 2-6 \mathrm{~mm}$, ápice agudo, mucronado, margem levemente denticulada, algo revoluta, coriáceas na base, papiráceas ou cartáceas na porção superior, densamente híspidas e pontuado-glandulosas, estrigosas nas margens, trinérveas, brácteas involucrais internas estreitamente oblongas ou oblongo-lanceoladas, 6-7×1,5-2 mm, ápice longamente-acuminado com margem ciliado-vilosa, rígidas na base, membranáceas no ápice, esparsamente pilosas e pontuado-glandulosas, sobretudo no ápice, multinérveas. Receptáculo levemente convexo, páleas conduplicadas, carenadas, oblongo-lanceoladas, 6-9×1,5-1,8 mm, ápice longamente acuminado, margem inteira a laciniado-setosa e moderadamente pilosas no ápice. Flores do raio 10-14 por capítulo, pistiladas, unisseriadas, liguliformes, corola $8-15 \times 3 \mathrm{~mm}$, tubo 1,5-3 mm compr., limbo estreitamente elíptico ou estreitamente oblongo, ápice tridentado, pubescentes no tubo, moderadamente setosas e pontuadoglandulosas na face abaxial do limbo, amarelas. Estilete bífido, pubescente nos ramos. Flores do disco 60-100, monoclinas, corola tubulosa, 4-5 $\mathrm{mm}$ compr., tubo 0,6-1 mm compr., pentadentadas, lacínias 0,6-0,8 mm compr., glabras ou com algum tricoma setoso, pontuado-glandulosas no ápice, amarelas a amarelodouradas. Anteras com tecas enegrecidas, apêndice oval, pontuado-glanduloso, base aguda. Estilete bífido, ramos pubérulos com um apêndice piloso no ápice. Cipselas obovóides, sem constrição sob o papilho, as do raio tríquetras, as do disco lateralmente comprimidas, 3,5-4 mm compr., curtamente alado-lobadas nos ângulos, tuberculadas, glabras, castanho-claras. Papilho formado por duas (três nas cipselas do raio) aristas curtíssimas e quase iguais, às vezes ausentes, de 


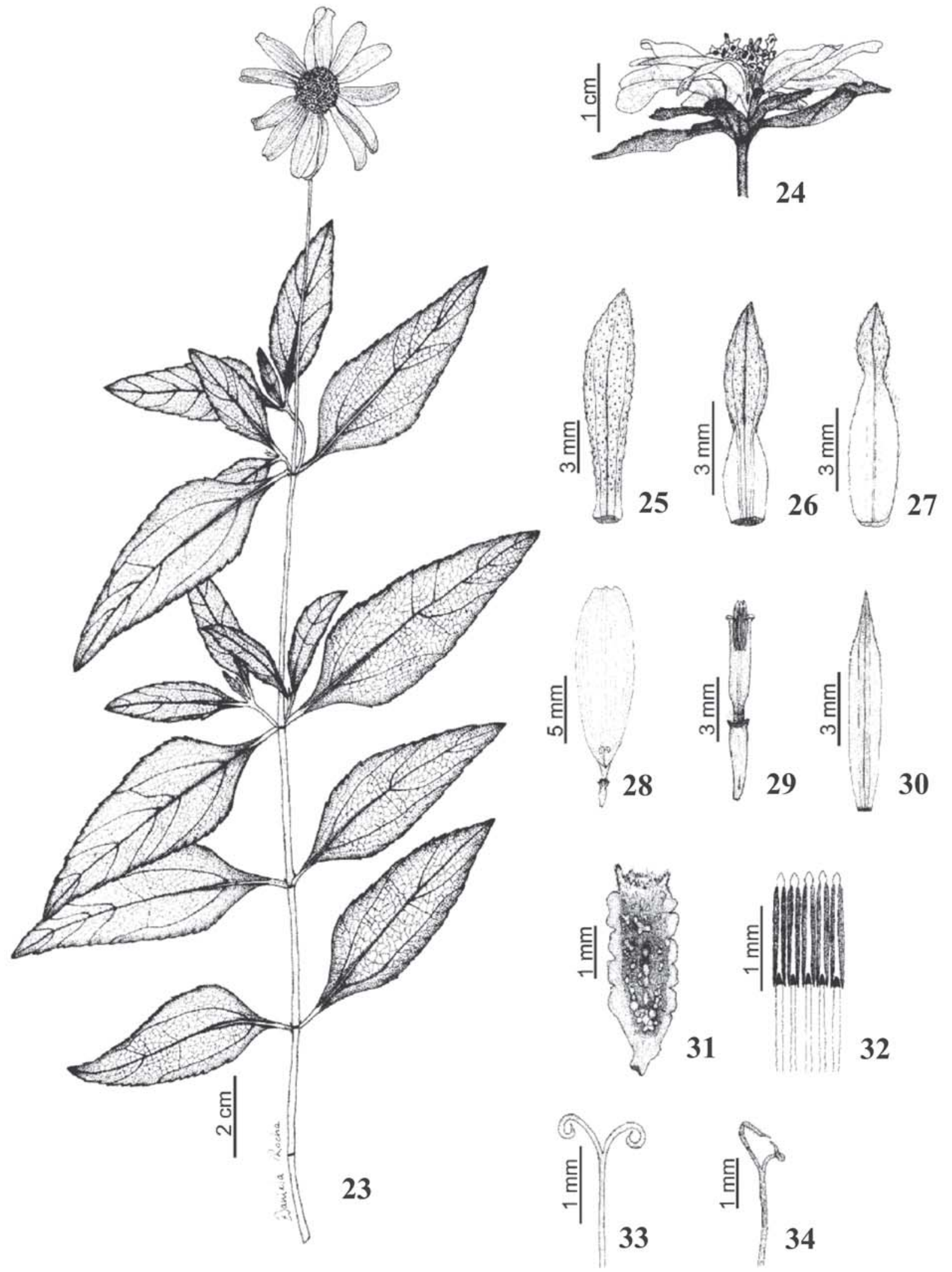

Figuras 23-34. Angelphytum tenuifolium (Hassl.) H. Rob. 23. Ramo florido. 24. Capítulo. 25-27. Brácteas involucrais. 28. Flor do raio. 29. Flor do disco. 30. Pálea. 31. Cipsela do disco. 32. Anteras. 33-34. Ápice do estilete das flores do raio e do disco (Mondin 2940). 
0,2-0,5 mm compr., entremeadas por escaminhas laciniadas de ca. $0,1 \mathrm{~mm}$ compr.

Material selecionado: BRASIL. Rio Grande do Sul: Derrubadas, 5/IV/2003, fl. fr., Mondin 2940 (HASU). Giruá, estrada velha entre Giruá e Santa Rosa, 21/II/1984, fl. fr., Bueno et al. 3984 (HAS). Nonoai, ad fl. Uruguai, III/1945, fl., Rambo 28172 (PACA). Pirapó, Passo do Auto, sanga Santa Maria, 26/V/1989, fr., Brack et al. s.n. (MPUC 9096).

Robinson (1984) cita a espécie apenas para a Argentina e o Paraguai. A espécie ocorre em locais úmidos e semi-sombreados de margens de matas e beira de caminhos. Foi coletada com flores e frutos de janeiro a maio e julho.

4. Viguiera nudicaulis (Pers.) Baker, Fl. bras. 6(3): 228. 1884. Tipo: Uruguai, Maldonado, 1826-1830, Capt. King 40 (holótipo K; fragmento do holótipo US).

Rudbeckia nudicaulis Pers., Syn. pl. (Persoon) 2: 477. 1806. Rhysolepis nudicaulis (Pers.) H.Rob. \& A.J. Moore, Proc. biol. soc. wash. 117(3): 429. 2004.

Fig. 35-44

Subarbusto decumbente ou subereto, ramos ascendentes, 0,3-0,5 $\mathrm{m}$ de altura, ramificado desde a base ou pouco ramificado, com xilopódio, funcionalmente homóico. Caule cilíndrico, estriado, piloso-pubescente, com tricomas longos eretos e curtos adpressos, purpúreo, folhoso na base e na porção mediana, áfilo no ápice. Folhas simples, opostas, as superiores, às vezes, alternas, lanceoladas a oblongas, 4-7×0,7-3 cm, ápice agudo ou obtuso, cuspidado ou mucronado, base levemente cuneada, atenuada ou arredondado-atenuada, margem serrulada ou inteira na metade inferior, paucisserrulada a paucisserreada na metade superior, cartáceas, híspido-setosas em ambas as faces, sobretudo sobre as nervuras, trinérveas acima da base, sésseis ou curtamente pecioladas, pecíolo 0-0,3 cm compr., híspido-setoso. Capítulos radiados, homógamos, solitários no ápice dos ramos, longamente pedunculados, pedúnculos $9-26 \mathrm{~cm}$ compr., pilosopubescentes, com tricomas longos eretos e curtos adpressos, albo-vilosos na base do capítulo, geralmente ebracteados, às vezes, com uma bráctea linearlanceolada com 0,5-1 cm compr. Invólucro campanulado, 9-14 mm alt., 8-17 mm diâm., brácteas involucrais 2-3-seriadas, aproximadamente com o mesmo tamanho, ou a série externa de menor tamanho, estreitamente oblongas, oblongo-lanceoladas ou linearlanceoladas, 9-14×1,5-4,5 mm, ápice acuminado, mucronulado, coriáceas e tuberculado-estrigosas na base, cartáceas e estrigoso-setosas para o ápice, margem longo-ciliada, trinérveas a multinérveas. Receptáculo convexo, páleas conduplicadas, carenadas, oblongo-lanceoladas ou estreitamenteelípticas, 6-8×2-2,5 mm, ápice agudo ou acuminado, margem inteira em toda a extensão ou paucidentada no ápice, pubérulas na parte superior sobre a carena. Flores do raio 9-15 por capítulo, neutras, unisseriadas, liguliformes, corola $13-21 \times 4-8 \mathrm{~mm}$, tubo 1-2 mm compr., limbo elíptico ou oblongo, ápice 2-3-dentado, moderadamente pubérulas no tubo, na base e sobre as nervuras na face abaxial do limbo, amarelas a amarelodouradas. Flores do disco 36-84, monoclinas, corola tubulosa, 4-5 mm compr., tubo 0,7-1 mm compr., pentadentadas a pentalobadas, lacínias 0,8-1,3 mm compr., pubérulas nas lacínias e, às vezes, no tubo, amarelas a amarelo-douradas. Anteras com tecas enegrecidas, apêndice oval, pontuado-glanduloso, base aguda. Estilete bífido, ramos pubérulos com um apêndice piloso no ápice. Cipselas oblanceoladas, algo comprimidas, mais ou menos 4-angulosas, 3,5-5 mm compr., seríceas, castanhas. Papilho formado por duas aristas paleáceas, membranáceas, quase iguais, com 2,5-3 mm compr., com escamas intermediárias de igual comprimento ou algo menores que as aristas, unidas até o ápice, que é lacerado.

Material selecionado: BRASIL. Rio Grande do Sul: Caçapava do Sul, a $8 \mathrm{~km}$ da cidade, na rodovia para Bagé, 15/X/1979, fl., Mattos et al. 19718 (HAS). Capão do Leão, I.A.S., 14/XI/1955, fl., Sacco 406 (PEL). Guaíba, fazenda São Maximiano, 27/X/2001, fl. fr., Mondin 2386 (HASU). Minas do Leão, na estrada para o Cerro do Roque, 29/IX/2001, fl., Mondin \& Iob 2251 (HASU). Pelotas, 18/XI/1955, fl., Sacco 418 (PACA). Pinheiro Machado, a $3 \mathrm{~km}$ da cidade, na rodovia para Bagé, 18/I/1979, fl., Mattos \& Assis 19213 (HAS). Porto Alegre, morro Santa Tereza, 24/X/1958, est., Pabst 4570 (LP). Santana do Livramento, cerro Palomas, 13/IV/2003, fl., Mondin \& Magenta 2951 (HASU). São Francisco de Assis, RS 241, 12/II/1999, fl., Knob \& Bordignon 5966 (SALLE). São Lourenço, BR 116, em direção a Cristal, 24/XI/2000, fl., Mondin 2081 (HASU). Viamão, Itapuã, 24/XI/2002, fl. fr., Mondin 2840 (HASU).

A espécie foi, até o presente, citada apenas para o Uruguai (De Candolle 1836; Baker 1884; Blake 1918; Robinson 2004). Ocorre em solos secos da vegetação campestre e foi coletada com flores e frutos de setembro a fevereiro e em abril, com predomínio em novembro. 


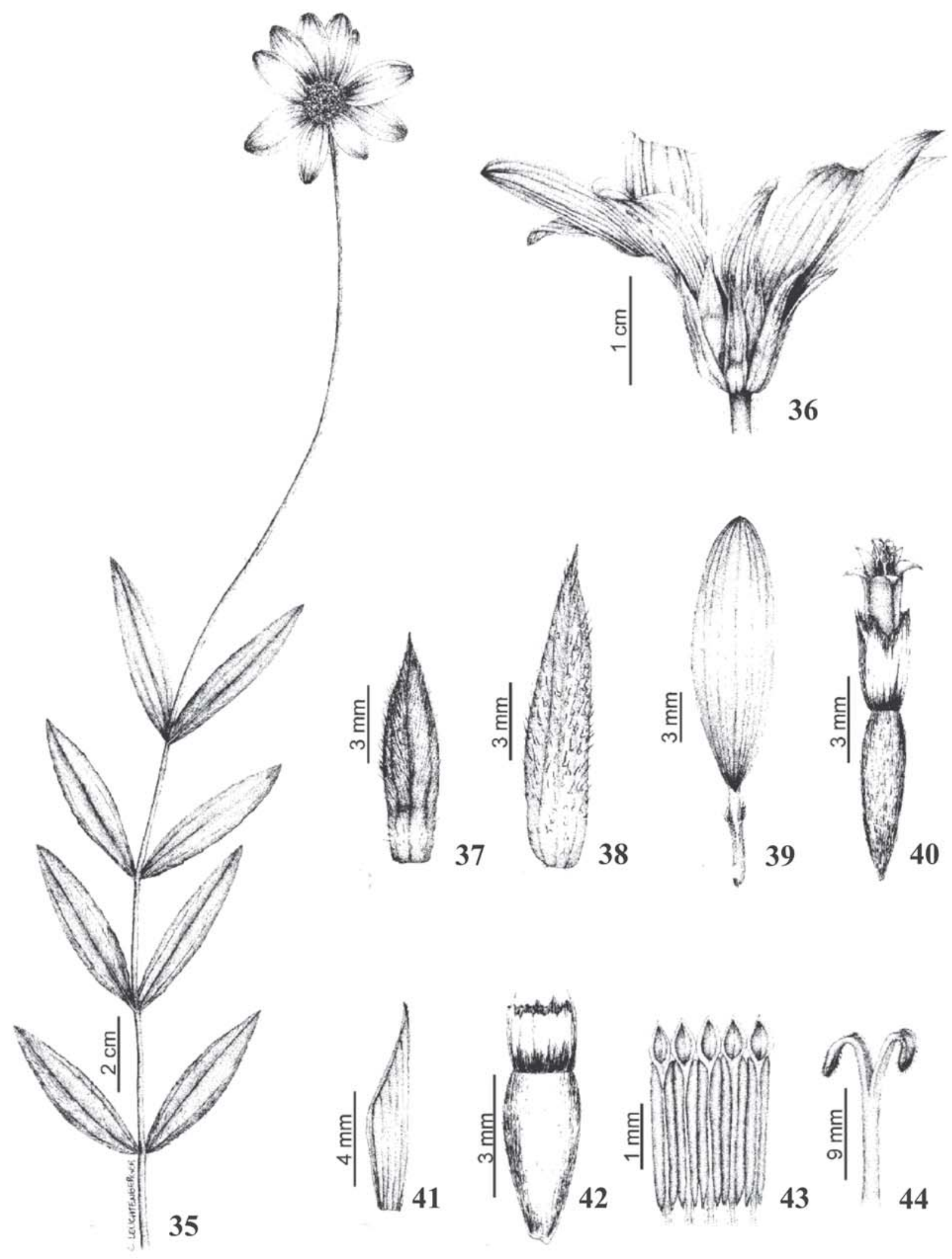

Figuras 35-44. Viguiera nudicaulis (Pers.) Baker. 35. Ramo florido. 36. Capítulo. 37-38. Brácteas involucrais. 39. Flor do raio. 40. Flor do disco. 41. Pálea. 42. Cipsela. 43. Anteras. 44. Ápice do estilete (Mondin 2081). 


\section{Agradecimentos}

O autor agradece à Dra. Ilsi Iob Boldrini, do CPGBotânica da Universidade Federal do Rio Grande do Sul, pela orientação da Tese de Doutorado "Levantamento da tribo Heliantheae Cass. (Asteraceae), sensu stricto, no Rio Grande do Sul, Brasil", da qual foi extraído este artigo; a Caroline Leuchtenberger, Daniela Rocha e Micheline Vergara pelas confecções das ilustrações; à Comissão Editorial e aos revisores pelas correções e sugestões.

\section{Referências bibliográficas}

Baker, J.G. 1884. Compositae IV: Helianthoideae. Pp. 19-268. In: C.F.P. von Martius \& A.W. Eichler (eds.). Flora brasiliensis. v.6, pars 4. F. Fleischer, Lipsiae. Munchen. Barroso, G.M. 1991. Sistemática de angiospermas do Brasil. Viçosa, UFV, Impr. Univ., v.3.

Blake, S.F. 1918. A revision of the genus Viguiera. Contributions from the Gray Herbarium of Harvard University 54: 1-205.

Bremer, K. 1994. Asteraceae: cladistics and classification. Portland: Timber Press.

Cabrera, A.L. 1963. Flora de la provincia de Buenos Aires. Compuestas. Buenos Aires, Colecion Cientifica del INTA, v.4.

Cabrera, A.L. 1974. Compositae. v.6. Pp. 106-554. In: A. Burkart (org.). Flora Ilustrada de Entre Rios (Argentina). Buenos Aires, Colecion Cientifica del INTA.
Cruden, R.W. \& Lloyd, R.M. 1995. Embryophytes have equivalent sexual phenotypes and breeding systems: Why not a common terminology to describe them? American Journal of Botany 82(6): 816-825.

De Candolle, A.P. 1836. Prodromus Systematis Naturalis Regni Vegetabilis. v.5. Paris, Treuttel \& Würtz.

Harris, J.G. \& Harris, M.W. 2001. Plant identification terminology: an illustrated glossary. 2 ed. Spring Lake, Spring Lake Publishing.

Holmgren, P.K. \& Holmgren N.H. 1998-2006. Index Herbariorum. New York Botanical Garden. Disponível em http://sciweb.nybg.org/science2/IndexHerbariorum.asp. (Acesso: 20/janeiro/2006).

Jansen, R.K. 1985. The systematics of Acmella (AsteraceaeHeliantheae). Systematic Botany Monographs 8: 1-115.

Malme, G.O.A.N. 1899. Die Compositen der ersten Regnellschen Expedition. Bihang til Kongliga Svenska Vetenskaps-akademiens Handlingar 32(5): 59-68.

Malme, G.O.A.N. 1931. Die Compositen der zeeiten Regnellschen Reise. I. Rio Grande do Sul. Arkiv för Botanik 24(6): 1-89.

Radford, A.E.; Dickson, W.C.; Massey, J.R. \& Bell, C.R. 1974. Vascular plant systematics. New York, Harper \& Row.

Robinson, H. 1984. Studies in the Heliantheae (Asteraceae), XXXIV: redelimitation of the genus Angelphytum. Proceedings of the Biological Society of Washington 97(4): 961-969.

Robinson, H. 2004. New species and new combinations in Rhysolepis (Heliantheae: Asteraceae). Proceedings of the Biological Society of Washington 117(3): 423-446.

Santos, J.U.M. 2001. O gênero Aspilia Thou. (AsteraceaeHeliantheae) no Brasil. Belém, Museu Paraense Emílio Goeldi. 